\title{
Dissecting the Spirit of Gezi: Influence vs. Selection in the Occupy Gezi Movement
}

\author{
Ceren Budak, Duncan J. Watts
}

\section{Microsoft Research}

Abstract: Do social movements actively shape the opinions and attitudes of participants by bringing together diverse groups that subsequently influence one another? Ethnographic studies of the 2013 Gezi uprising seem to answer "yes," pointing to solidarity among groups that were traditionally indifferent, or even hostile, to one another. We argue that two mechanisms with differing implications may generate this observed outcome: "influence" (change in attitude caused by interacting with other participants); and "selection" (individuals who participated in the movement were generally more supportive of other groups beforehand). We tease out the relative importance of these mechanisms by constructing a panel of over 30,000 Twitter users and analyzing their support for the main Turkish opposition parties before, during, and after the movement. We find that although individuals changed in significant ways, becoming in general more supportive of the other opposition parties, those who participated in the movement were also significantly more supportive of the other parties all along. These findings suggest that both mechanisms were important, but that selection dominated. In addition to our substantive findings, our paper also makes a methodological contribution that we believe could be useful to studies of social movements and mass opinion change more generally. In contrast with traditional panel studies, which must be designed and implemented prior to the event of interest, our method relies on ex post panel construction, and hence can be used to study unanticipated or otherwise inaccessible events. We conclude that despite the well known limitations of social media, their "always on" nature and their widespread availability offer an important source of public opinion data.

Keywords: social networks; social movements; ex post panels; Twitter

Citation: Budak, Ceren, and Duncan J. Watts. 2015. "Dissecting the Spirit of Gezi: Influence vs. Selection in the Occupy Gezi Movement." Sociological Science 2: 370-397.

Received: December 20, 2014

Accepted: February 4, 2015

Published: July 22, 2015

Editor(s): Jesper Sørensen, Sarah Soule

DOI: $10.15195 / \mathrm{v} 2 . \mathrm{a} 18$

Copyright: (C) 2015 The Author(s). This open-access article has been published under a Creative Commons Attribution License, which allows unrestricted use, distribution and reproduction, in any form, as long as the original author and source have been credited. (0)(1)
$\mathrm{O}$ N May 28, 2013 a small group of roughly 50 environmentalists occupied Gezi Park, an urban park adjacent to Taksim Square in central Istanbul, to protest the Turkish government's announced plan to remove the park in order to make way for a shopping mall. Subsequent events are now well known. A violent attempt by the police the next day to disperse the protestors was met with public outrage, triggering much larger protests both in Gezi Park and Taksim Square as well as in other parts of Istanbul and other cities across the country. These protests, in turn, triggered successive cycles of police repression and further protests-a pattern that persisted at various levels of intensity and extent over the summer of 2013. Accompanying the rapid growth in the size and geographical extent of the protests was an equally dramatic shift in focus; that is, what began as a specifically environmental protest quickly metastasized into a generalized outpouring of public resentment against the increasingly restrictive civil rights policies of Prime Minister Recep Tayyip Erdoğan and the governing AKP party (Bezmez, 2013; Kuymulu, 2013; Atay, 2013; Ete, 2013). Even as it spread well beyond its origins in Gezi park, however, the protest movement continued to be known as the "Gezi uprising" or 
the "Occupy Gezi movement;" thus we use these labels interchangeably throughout this article to refer to the protests that took place throughout Turkey between May 28 and Aug 1, 2013.

Reflecting the broad scope of the Gezi uprising, the composition of protestors also displayed striking demographic, geographic, socioeconomic and political diversity - an observation that was frequently highlighted in media reports ${ }^{1}$ (see, e.g., http://en.wikipedia.org/wiki/2013-14_protests_in_Turkey). The diversity of the protest body - and equally, the apparent solidarity among groups that were traditionally indifferent, or even hostile, to one another-was subsequently held up as a central, even defining, feature of the movement ${ }^{2}$ (White, 2013; Kuymulu, 2013; Sözalan, 2013; Taştan, 2013). Over the course of the uprising, participants and observers increasingly spoke of "the Gezi spirit," referring to "the coming together of a great diversity of protesters who spontaneously self-organized into a different type of sociality, briefly constructing a free space based on the principles of horizontality, solidarity, mutual aid, and direct democracy." (Collective, 2014).

But what constituted the spirit of Gezi? Observations of the sort just described clearly imply that participants' attitudes towards one another were profoundly influenced by their participation in the protests themselves. According to this "influence" account, therefore, one would expect to see participants' expressed positions shift over the course of the protests to a greater degree than those of non-participants; moreover, one might also expect to see these changes persist even after the protests had formally ended. But there is another possible explanation for the observed spirit of Gezi-namely that individuals who were already sympathetic to other political groups were more likely to participate than those who were not. And according to this "selection" account, the observed solidarity among protesters would not necessarily imply any greater shift in their positions than for non-participants, either during or after the protests.

Clearly these influence and selection explanations constitute distinct views on the origins of the Gezi spirit, corresponding to different causal mechanisms and also making different predictions about opinion change over time. Nevertheless, they can be difficult to disambiguate on the basis of journalistic reports of the Occupy Gezi movement and even the handful of ethnographic studies that were performed, for two reasons. First, because observational methods of this sort were focused almost exclusively on the participants in the movement, comparisons between participants and non-participants are difficult to make; hence selection effects are likely to be underestimated. Second, because participants can be sampled only after the events in question have attracted the attention of researchers, before and after comparisons are likewise difficult to make. ${ }^{3}$ Constructing and repeatedly polling representative panels, meanwhile, is impractical both on account of its expense and also the likelihood of government interference.

This difficulty of disambiguating between influence and selection mechanisms in explaining the effects of the Gezi uprising also applies more generally to studies of social movements, many of which either lack a control group (Demerath, Marwell, and Aiken, 1971; Maidenberg and Meyer, 1970; Marwell, Aiken, and Demerath, 1987; Abramowitz and Nassi, 1981; Nassi and Abramowitz, 1979; Whalen and Flacks, 1980) or lack data prior to and/or after the movement (Fendrich, 
1974, 1977; Fendrich and Krauss, 1978; Fendrich and Tarleau, 1973; Maidenberg and Meyer, 1970; Abramowitz and Nassi, 1981; Nassi and Abramowitz, 1979; Whalen and Flacks, 1980). Moreover, it is difficult to overcome these methodological shortcomings even when they are recognized, as is highlighted by two notable exceptions to the general pattern. First, McAdam (1989) studied the political and personal consequences of high-risk activism using survey data collected on 212 participants in the 1964 Mississippi Freedom Summer project as well as 118 "'no-shows" (individuals who applied, were accepted, but did not take part in the project). By comparing future attitudes of participants with no-shows, who presumably had similar ex ante attributes, McAdam was able to more accurately identify opinion change due to participation, finding that participants were more politically active throughout the sixties than the no-shows and remained so afterwards. Second, Sherkat and Blocker (1997) analyzed data from a multi-wave panel conducted over 32 years to study antiwar, student, and civil rights protests and disambiguated selection from influence by controlling for factors that predicted protest participation, finding that former protesters were different from their non-participant counterparts in politics, status attainment, religion, and family-related attitudes ${ }^{4}$.

Although both these studies succeeded to some extent ${ }^{5}$ in disambiguating between selection and influence, as noted above they also illustrate the difficulty of doing so. Freedom Summer was planned well in advance, thereby affording McAdam sufficient notice to design and implement his survey prior to the event itself. Sherkat and Blocker's panel, meanwhile, was designed by other researchers (Jennings et al., 2005) with a much broader focus in mind, hence its ex post application to the protest movements of interest to Sherkat and Blocker was largely serendipitous. In contrast with these two cases, many events of interest to social movements researchers are, like the Gezi uprising, neither anticipated nor serendipitously suited to preexisting panels. Moreover, even when researchers are aware that an event of interest is about to unfold and could in theory design and implement a panel ex ante, it may be in a location such as Turkey in 2013 where for a variety of reasons, including government hostility to public opposition, traditional survey methods are rendered problematic. In such situations, how should researchers proceed?

To answer this question we turn to a source of data that is increasingly popular among students of social movements-namely Twitter. Although as we will discuss in Data and Methods, Twitter data potentially suffers from a number of important biases, it has three very important advantages for our question. First, it captures the opinions of non-participants as well as participants and of supporters of the government as well as opponents. Second, it is possible to identify the political leanings of both participants and non-participants prior to the beginning of the uprising and hence to construct panels of users, thereby allowing us to track changes over time, and also to avoid some of the inference problems that have been raised with respect to Twitter data in particular and social media data in general (Tufekci, 2014). And third, it is an "always on" data collection method that does not require specifically designed (and funded) panels, hence can be used to study the impact of unanticipated events as well as anticipated ones. In contrast with traditional panels, which are both designed and assembled in advance of the 
events of interest, panels can be constructed from Twitter data after the fact; hence we call our method ex post panel construction.

The remainder of this article proceeds as follows. In the next section we describe related work in the intersection of social media and social movements and outline our method of panel construction. In Data and Methods we present some descriptive statistics concerning the use of Twitter during the Gezi uprising and describe our panel construction method in detail. In Results, we present our main hypotheses and results, finding evidence for both selection and influence. Finally, in Discussion we discuss the broader implications of our findings, the limitations of our ex post panel method, and suggestions for future work.

\section{Related Work}

In reviewing previous work at the intersection of social media and social movements we find it helpful to draw a distinction between studies that view social media as a causal factor driving protest movements and those that view social media as a source of data for understanding protest movements generally. Clearly it is possible for social media to perform both functions simultaneously. On the one hand, by opening new channels of communication-between activists on the ground, between activists and government actors, and between both groups and the larger publics they each seek to influence-social media clearly has the potential to impact the day-to-day dynamics and even the longer-term outcomes of protest movements. On the other hand, the very same communication technology also generates a digital record of the events that took place, the actors who participated, and the interactions between actors. Social media is therefore both a measurement technology for quantifying social change-analogous to traditional survey tools or participant observation-and also a communication technology that is part of the process of social change that it is measuring. ${ }^{6}$ Some degree of ambiguity notwithstanding, however, studies of social media and social movements nevertheless tend to emphasize one of these two views of social media data over the other.

In the first category, for example, Etling (2013) emphasizes the value of the Internet for political action, stating explicitly that the protests associated with the Arab Spring were Internet-enabled. ${ }^{7}$ Tufekci and Wilson (2012) also argue for the value of social media in social movements: through a survey study of Egypt's Tahrir Square protesters, the authors conclude that social media use, Facebook in particular, provided new sources of information and was crucial in influencing individual decisions about protest participation. ${ }^{8}$ Gleason (2013) argues that microblogs such as Twitter exposed social media users to more diverse perspectives during the Occupy Wall Street protests, thereby creating a more engaged and informed group of citizens as well as facilitating their participation in the political process. Similarly, Khamis and Vaughn (2011) emphasizes the value of social media as tools of civic engagement and citizen journalism so much as to suggest that these characteristics are the ones that "tilted" the political and communication balance in Egypt in favor of freedom fighters and political activists. ${ }^{9}$ González-Bailón, Borge-Holthoefer, and Moreno (2013), focusing on the indignados movement in Spain, suggest that online social networks facilitated the movement more efficiently than their offline 
counterparts by enabling fast diffusion of ideas and organizational details. ${ }^{10} \mathrm{Fi}-$ nally, and in contrast to the generally optimistic tone of other studies, Lewis, Gray, and Meierhenrich (2014) use the "Save Dafur" campaign on Facebook to argue that cause-related online activism generates surprisingly little "real" activism, as measured either by donations or recruitment of new members.

In the second category, Starbird and Palen (2012) use Twitter to study information diffusion during the 2011 Egyptian revolution, finding that the crowd indeed provided value by expressing solidarity and performing information processing through recommendation and filtering. González-Bailón et al. (2011) study dynamics of protest recruitment in a social network-again focusing on the indignados movement that took place in Spain in May 2011-finding that early participants (characterized as the leaders of the recruitment process) did not have a typical topological position but spreaders (characterized as seeds of message cascades) tended to be more central in the network. Weber, Garimella, and Batayneh (2013) use Twitter data to quantify the degree of religious polarization among Egyptian Twitter users, finding: (1) that political Islamism is correlated with overall religiosity and charitable giving; and (2) that followers of the Egyptian Muslim Brotherhood are more cohesive than the secular opposition. Etling et al. (2009) explore the structure and content of the Arabic blogosphere using link analysis, term frequency analysis, and human coding of individual blogs, mapping the ideas and viewpoints of a diverse group of people, including Egyptian secular activists, Egyptian Muslim Brotherhood members, and Kuwaiti reformists ${ }^{11}$. Finally, Hanna (2013) applies supervised learning techniques to Facebook data to study the April 6 Youth movement in Egypt, categorizing each Facebook post with respect to its mobilization characteristic (offline coordination, Internet action, reporting on events, etc.), and mapping the progression of mobilization techniques through the course of the movement.

In terms of this simple classification scheme our contribution falls squarely into the second category; that is, we make no claims regarding the effect of Twitter on the outcome of the Gezi uprising, but rather use it exclusively to understand the origins of the observed cohesiveness between its participants. To this end, we introduce a methodology-which we label ex post panel construction-that to our knowledge is novel in the context of social movement analysis. ${ }^{12}$ First, as described in Constructing the Panel, we identify a large sample of users who, based on their retweet behavior in the 17 months leading up to the Gezi movement, can be identified as supportive of one of the four major Turkish political parties prior to the start of the uprising on May 28, 2013. We then restrict this sample to users who remained active on Twitter over the course of the entire time of the Gezi uprising, from May 28 to August 1, and for at least five months afterwards, thus generating a panel of users retrospectively. Second, as related in Constructing the Panel, we then split the panel into two parts-"non-participants" and "participants," where participants are identified by their usage of at least one Gezi-related hashtag during the protest. In addition, we further split participants into "verified physical" and "other" participants where, as described in Identifying Physical Participation, verified physical participants are identified as participants who checked in to protest locations through Foursquare. Third, to account for uneven activity over time, in 
particular compositional changes in the daily active population, we aggregate user activity for three periods: "pre-Gezi," comprising the 17 months prior to the movement (January 1, 2012 to May 28, 2013); "during Gezi," comprising the roughly two months of the "official" uprising (May 28, 2013 to August 1, 2013); and "postGezi," comprising the five months after the movement (August 1, 2013 to January 1, 2014). And finally, given the unequal distribution of activity over panel members, we rely on mixed-effects modeling to address the research questions of interest.

\section{Data and Methods}

With $40 \mathrm{M}$ active social media accounts ( $52 \%$ of its population), Turkey has a rather high social media penetration (Kemp, 2015). In addition, social media usage is unusually political in Turkey: according to Pew (2012), 57 percent of social media users in Turkey share their views about politics on social networking sites, compared to a median of 34 percent across the globe. This heavy reliance on social media is accentuated in the particular case of the Gezi uprising. As has been documented elsewhere, the lack of trust in Turkish news media drove Gezi protesters to seek and share information online through social media; Konda (2014) shows that 85 percent of protesters shared uprising related utterances on social media. In addition, many Twitter users specify their location in their profiles in a free form text. We parsed this information and identified sub-strings that matched particular cities, thereby identifying the location of 1,503,910 Turkish Twitter users. Impressively, the correlation of population distribution over cities and the distribution of Twitter accounts is 0.975 , suggesting that Twitter usage in Turkey is not only extensive but also geographically representative.

\section{\#Gezi participation}

Turning now to Twitter usage that is specific to the Occupy Gezi movement, we classify Twitter users as "participants" if they used any of the uprising hashtags, such as \#direngezi, \#occupygezi, or \#geziparki ${ }^{13}$ at least once between May 28 and August 1, 2013, the period during which the physical protests took place. In this manner, we identified 1,289,320 \#Gezi participants, who between them shared $12,070,622$ \#Gezi related tweets. Clearly this criterion for participation is relatively weak compared with, say, physical occupation of the park (in Identifying Physical Participation we will define a separate category of "physical participants" using Foursquare check-ins), and is more accurately thought of as participation in the social media conversation around the movement. Nevertheless, in an authoritarian environment such as Turkey in 2013, even participating publicly in a conversation about an uprising connotes some nontrivial level of risk ${ }^{14}$; moreover, as we will see, it corresponds to significant differences vis-a-vis non-participants.

Figure 1 provides a temporal overview of \#Gezi activity, showing the number of tweets per day (Figure 1(a)) and per hour (Figure 1(b)). As Figure 1(a) shows, there are three main spikes in activity, corresponding to the three most consequential days of the movement (Hürriyet, 2013): on May 31, after the "biggest dawn operation" on environmental activists that caused social media outrage; on June 

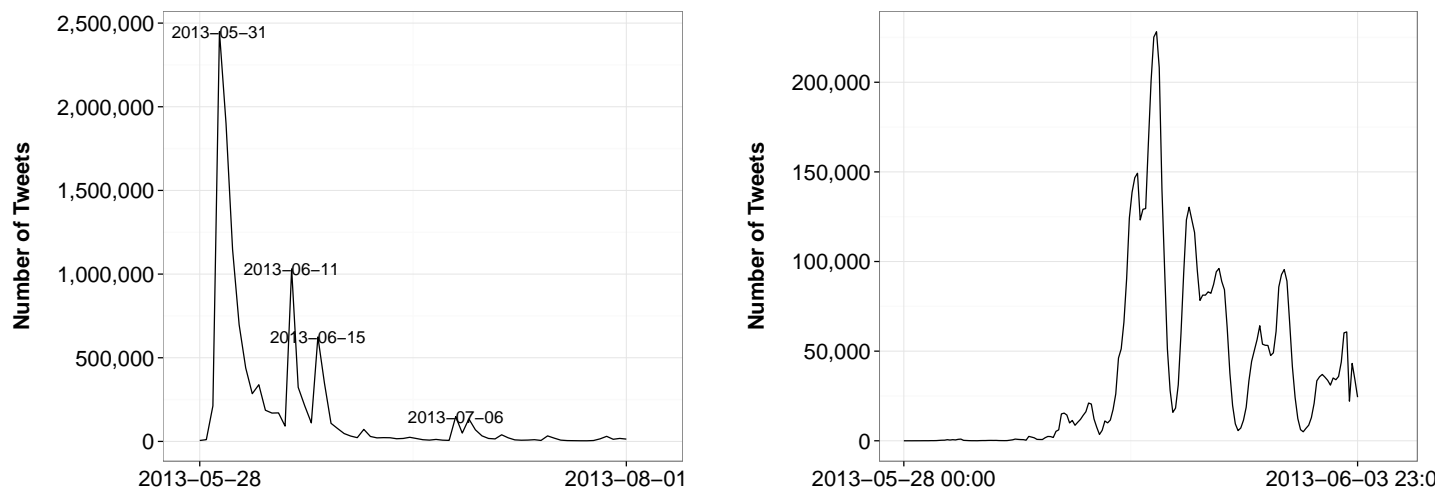

Figure 1: Gezi activity on Twitter: A. provides an overview of tweets that include the uprising hashtags per day between May 28 and August 1, 2013. B. provides a more detailed, per hour view, for the first week of the movement. The first days of the movement did not receive much attention, and there is a huge spike in participation on May 31 after the brutal police crackdown.

11, during the "harshest crackdown since the movement started"; and on June 15 , following a police attack that "ended the days-long occupation of the park." Figure 1(b), moreover, shows a daily pattern corresponding to the hours when protestors were physically most and least active. Although the close correspondence between these activity spikes and events on the ground is encouraging, the steep dropoff in \#Gezi activity that is evident in Figure 1 does not necessarily indicate declining engagement in the movement or even in the corresponding social media conversation. Rather, as Tufekci (2014) has argued, it could just be that once those involved had signaled their interest, they were likely to drop the hashtag in their conversations in order to conserve space within the 140-character limit. In other words, even if hashtag usage is a reliable indicator of initial involvement, it is not a reliable indicator of ongoing involvement. Compounding this inference problem are two others. First, activity on Twitter is highly heterogenous, both across users and also within users over time; thus the composition of users active on Twitter may differ substantially from day to day. Second, interview-based studies (Konda, 2014; MetroPOLL, 2013) reveal that a large fraction of Gezi participants were apolitical prior to the movement. Since we are interested in comparing selection versus change in political attitudes over the course of the movement, our research design requires us to consider only individuals for whom political views can be identified prior to the onset of the protests ${ }^{15}$.

As described earlier, we address these problems by constructing a panel of users who were politically active prior to the uprising and whom we can follow throughout the movement as well as in its aftermath. Our approach has four main advantages. First, by following the whole panel for the entire period we avoid biases associated with any dropoff in hashtag usage. Second, by identifying users with political parties prior to the Gezi movement we can test both for preexisting political sympathies as well as for changes in attitudes during and after the movement. Third, by aggregating panel activity over three extended periods we minimize 
Table 1: Party Breakdown of the Grand National Assembly

\begin{tabular}{|c|c|c|c|c|c|}
\hline Party & Ideology & $\begin{array}{l}\text { Political } \\
\text { Position }\end{array}$ & $\begin{array}{l}\text { MP } \\
\text { Count }\end{array}$ & $\begin{array}{r}2011 \text { General } \\
\text { elections } \\
\text { Vote Share }\end{array}$ & $\begin{array}{r}2014 \text { Local } \\
\text { elections } \\
\text { Vote Share }\end{array}$ \\
\hline $\begin{array}{l}\text { AKP (Justice and Devel- } \\
\text { opment Party) }\end{array}$ & $\begin{array}{l}\text { Economic Liberalism, } \\
\text { Social conservatism }\end{array}$ & Center-right & 327 (59\%) & $50 \%$ & $46 \%$ \\
\hline $\begin{array}{l}\text { CHP (Republican Peo- } \\
\text { ple's Party) }\end{array}$ & $\begin{array}{l}\text { Kemalism (Nationalism, } \\
\text { Secularism), Social } \\
\text { democracy }\end{array}$ & Center-left & $134(24 \%)$ & $26 \%$ & $28 \%$ \\
\hline $\begin{array}{l}\text { MHP (Nationalist Move- } \\
\text { ment Party) }\end{array}$ & $\begin{array}{l}\text { Turkish nationalism, } \\
\text { Pan-Turkism, Social } \\
\text { conservatism }\end{array}$ & Far-right & $53(10 \%)$ & $13 \%$ & $15 \%$ \\
\hline $\begin{array}{l}\text { BDP(Peace and Democ- } \\
\text { racy Party) }\end{array}$ & $\begin{array}{l}\text { Social democracy, Kur- } \\
\text { dish nationalism }\end{array}$ & Far-left & $34(6 \%)$ & $7 \%$ & $6 \%$ \\
\hline
\end{tabular}

biases associated with compositional changes (i.e., that different individuals are more or less active on different days). And finally, by using mixed-effects models, we account for differences in activity levels of our panel members. ${ }^{16}$

\section{Identifying Political Affiliation}

Turkey's political system is based on a separation of powers between the executive branch, the legislative branch, and the judicial branch. Of these three, we will focus on the legislative branch, also known as the Grand National Assembly of Turkey, because it is the most representative, comprising 550 parliament members (MPs) who are elected to four-year terms by popular vote and who collectively represent all 81 provinces. In order for an MP to be elected under the auspices of an official political party, however, the party in question must attract at least 10 percent of the nationwide vote. An important consequence of this 10 percent threshold rule is that only four political parties attained representation in the 2011 elections: the governing AKP party and the three main opposition parties- $\mathrm{CHP}, \mathrm{MHP}$, and BDP. ${ }^{17}$ Table 1 shows the breakdown of parliamentary seats by party at the onset of the Gezi movement and describes their ideological similarities and differences (column 2). For example, the AKP and the MHP both value social conservatism; however this ideology is more central to the AKP identity, whereas the MHP is also defined by its nationalistic values. Similarly, the CHP and the MHP share Turkish Nationalism as a value, but the MHP espouses a more extreme (i.e., "far right") version compared to the CHP's more moderate stance. Finally, the BDP is strongly associated with Kurdish Nationalism and hence is at odds with both Turkish Nationalist parties, but especially with the MHP.

We establish correspondence between parliamentary representation and Twitter activity by identifying all Twitter accounts corresponding to Parliament members (The Grand National Assembly Deputy List, 2013), and finding that 85 percent of MPs have an active Twitter presence ${ }^{18}$ - significantly higher than for members of 
Table 2: Overview of Party presence on Twitter

\begin{tabular}{lrrrc}
\hline & $\begin{array}{c}\text { Number of } \\
\text { Twitter } \\
\text { Party }\end{array}$ & $\begin{array}{c}\text { Average } \\
\text { Number of } \\
\text { Tweets }\end{array}$ & $\begin{array}{c}\text { Average } \\
\text { Number of } \\
\text { Followers }\end{array}$ & $\begin{array}{c}\text { Average } \\
\text { Number of } \\
\text { Friends }\end{array}$ \\
\hline AKP & $259(59 \%)$ & 2,297 & 53,339 & 450 \\
CHP & $114(26 \%)$ & 2,227 & 38,715 & 599 \\
MHP & $40(9 \%)$ & 2,309 & 38,201 & 914 \\
BDP & $27(6 \%)$ & 1,433 & 59,882 & 255 \\
\hline
\end{tabular}

Congress in the United States (Hanna, 2013). Table 2 provides an overview of MP presence on Twitter, showing that the representation of each party is remarkably similar to its representation in Parliament (e.g., 59 percent of all MP Twitter users are AKP members, corresponding exactly to the AKP's share of seats in parliament). ${ }^{19}$ Table 2 also presents some high level statistics such as number of tweets, followers, and friends. For example, BDP MPs are the least active in posting on Twitter on average; however, they have a larger following (per member) than CHP and MHP MPs.

We are now in a position to identify party affiliations of politically engaged Twitter users in terms of their retweet behavior. ${ }^{20}$ Specifically, we would like to classify a user as a supporter of a particular party if the majority of his or her retweets are for MPs who belong to that party. ${ }^{21}$ We note, however, that this criterion involves a tradeoff between the size of our panel and our confidence in our classification scheme: the more retweets a user commits the greater our confidence in our classification for that user; however, the fewer users will qualify for our panel. Figure 2(a) illustrates the tradeoff, showing that 333,349 users in our data set retweeted at least one MP tweet prior to the Gezi uprising, but that more than 50 percent of those 333,349 users retweeted only one MP tweet. Therefore, to strike a balance between panel size and classification confidence, we choose ten retweets (prior to the onset of the uprising) as our threshold for inclusion in the panel, yielding a total of 31,518 users. ${ }^{22}$ For these users, we can now define the support a user $u_{i}$ gives to a particular party $p_{j}$ as:

$$
s_{i, j}=\frac{\left|R T_{i, j}\right|}{\sum_{k}\left|R T_{i, k}\right|}
$$

where $\left|R T_{i, j}\right|$ is the number times $u_{i}$ retweets an MP from party $p_{j}$ before the Gezi uprising. Next, we define the first party support for user $u_{i}$ as:

$$
s_{i, \max }=\max _{j} s_{i, j} .
$$

Moreover, noting that the Turkish electoral system allows each citizen to vote for only one party in any given election, we denote $u_{i}$ 's party affiliation as

$$
P_{i, \max }=\underset{j}{\arg \max } s_{i, j}
$$



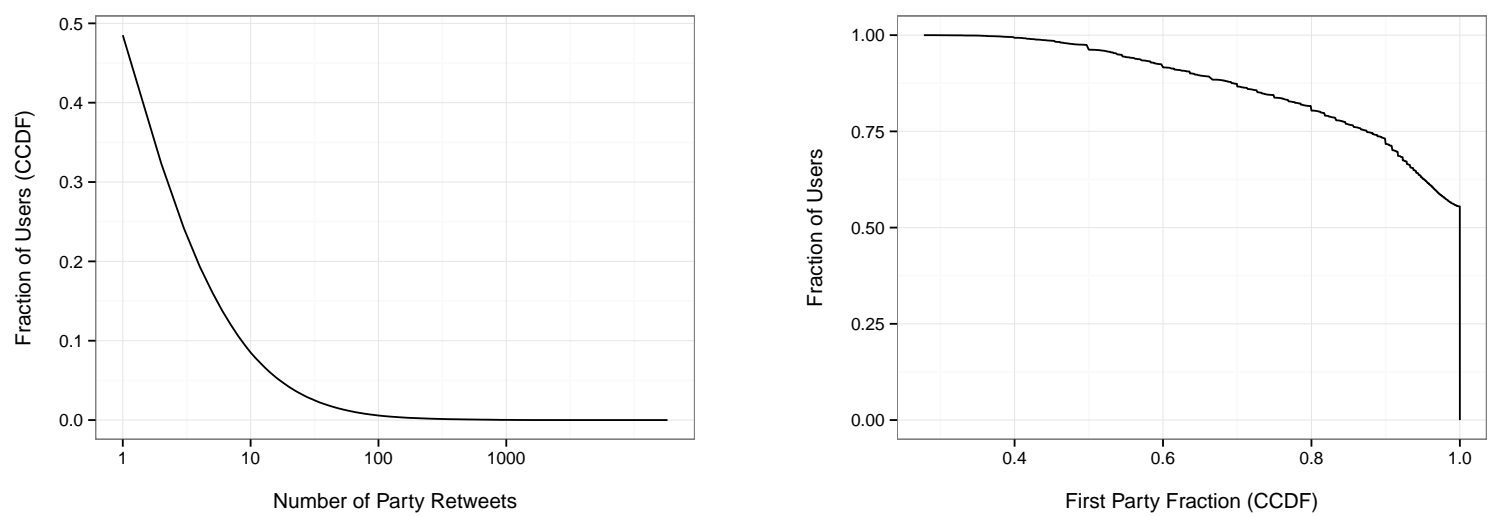

Figure 2: Party Support Analysis: A: CCDF of Number of Political Retweets B: Fraction of retweets that are in support of the most commonly supported party for each individual

\section{Constructing the Panel}

Figure 2(b) shows the distribution of $s_{i, \max }$ and indicates that over half of the politically active Twitter population exclusively supports one party $\left(s_{i, \max }=1\right)$. Moreover, 96 percent of users have $s_{i, \max } \geq 0.5$; thus we construct our panel based on these 30,323 users, of which about 60 percent are classified as supporting the AKP (i.e., the government), with 19 percent following the CHP, 15 percent the MHP, and 6 percent the BDP. Encouragingly, support for the MHP (the far right party) and the BDP (the far left party) in our panel closely matches that of the 2011 electoral vote shown in Table (column 3), while AKP support is somewhat higher and CHP (center-left party) support is somewhat lower than electoral support and more similar to the corresponding representation of MPs in parliament. Finally, based on the subset of 11,035 panel members for whom we can identify geolocations (see above), the correlation with the population (0.965) is similar to that for the total Turkish Twitter population noted previously.

Turning now to \#Gezi involvement, of the 30,323 politically-active users in our panel we further identify 14,274 (47 percent) as \#Gezi participants according to their Gezi-related hashtag usage as outlined previously, where the remaining 16,049 (53 percent) are labeled "non-participants." 23

As summarized in Table 3, we find that the most active \#Gezi participants in our panel were supporters of the center-left CHP (79 percent participation), which is also the dominant opposition party in Turkey, followed by the far-left BDP (69 percent), the far-right MHP (50 percent), and finally the governing AKP (34 percent), replicating the rank ordering obtained in interview-based studies (Konda, 2014; Genar, 2013). In addition, Figure 3 shows: (A) the CDF of the number of Gezi-related tweets of each \#Gezi participant from different parties; (B) the duration of involvement, computed as the number of days between the first and last Gezi-related tweet for each user, ${ }^{24}$ and (C) the CDF of the time of the first Gezirelated tweet for each user broken down by party. In other words, and consistent with Table 3, Figure 3 shows that CHP members were the most involved in the 
Table 3: Gezi Involvement of Political Party Supporters: The percentages in the third column indicate the fraction of party supporters that participated in Gezi and the percentages in the fourth column indicate the fraction of Gezi participants with at least one Gezi related Foursquare checkin.

\begin{tabular}{lrrr}
\hline Party & $\begin{array}{c}\text { Supporter } \\
\text { Count }\end{array}$ & $\begin{array}{c}\text { Supporters } \\
\text { Participating } \\
\text { in Gezi }\end{array}$ & $\begin{array}{c}\text { Supporters } \\
\text { with Gezi } \\
\text { checkins }\end{array}$ \\
\hline AKP & 18,313 & $6,207(34 \%)$ & $93(2 \%)$ \\
CHP & 5,830 & $4,604(79 \%)$ & $262(6 \%)$ \\
MHP & 4,339 & $2,190(51 \%)$ & $82(4 \%)$ \\
BDP & 1,841 & $1,273(69 \%)$ & $34(3 \%)$ \\
\hline
\end{tabular}

movement, whether measured in terms of overall involvement, duration, or time of first involvement. By the same measures, BDP supporters were the next most involved, followed by MHP and AKP supporters.

Overall, therefore, the composition of our panel is consistent with the representation of the main political parties in parliament, and also-with one notable exception-with other evidence about the relative involvement of the various parties. The exception is our finding that 34 percent of AKP (i.e., government) supporters "participated" in the movement, which is suspiciously high given the extremely low turnout of AKP supporters reported by other sources. To check whether usage of Gezi-related hashtags corresponded to legitimate support for the movement or to some other agenda (so-called "hashjacking"), we manually inspected tweets of a random sample of 15 supporters of each of the four parties who had used the uprising hashtags at least once. We coded each user as "supportive," "hostile," or "undecided" towards the Gezi uprising. Reassuringly, we found that 100 percent of the CHP-affiliated users, 80 of MHP-affiliated users, and 87 percent of BDP-affiliated users were indeed supportive of the Gezi movement (the remaining two BDP supporters were labeled undecided). For the opposition parties, therefore, we conclude that Gezi hashtag usage is a reasonable proxy for support. For AKP supporters, however, we found that 87 percent of the examined users were hostile towards the movement, suggesting that hashtag usage cannot be interpreted in the same way for AKP supporters as for supporters of the other three parties. Therefore, in Results, we restrict our analysis of influence versus selection to the three opposition parties.

\section{Identifying Physical Participation}

Social media renders participation in social movements relatively easy and safe, at least compared with more traditional forms of participation such as physical attendance at protests. As noted in Related Work, however, the impact of social media on social movements is a matter of dispute: although some authors argue that the relative ease of virtual participation is a positive development (Etling, 2013; Tufekci and Wilson, 2012; González-Bailón, Borge-Holthoefer, and Moreno, 2013), others question its value (Lewis, Gray, and Meierhenrich, 2014; Shulman, 2009), even going as far as to dismiss it as "slacktivism" (Morozov, 2009). Without trying 


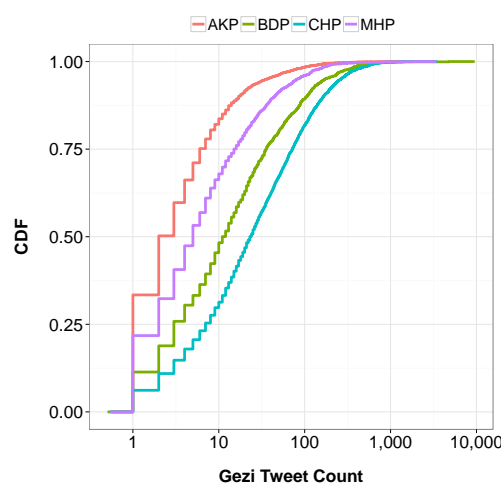

(a) Number of Gezi Tweets

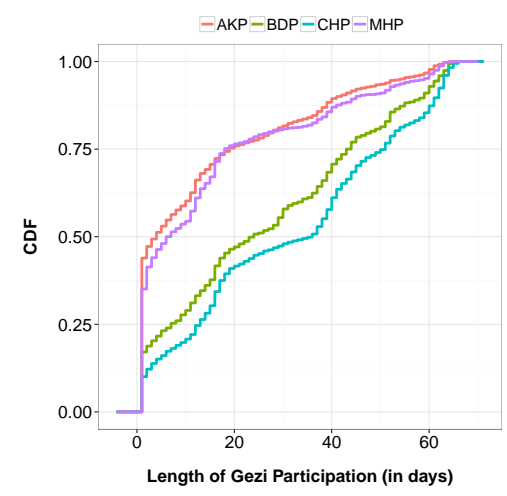

(b) Length of Gezi Participation

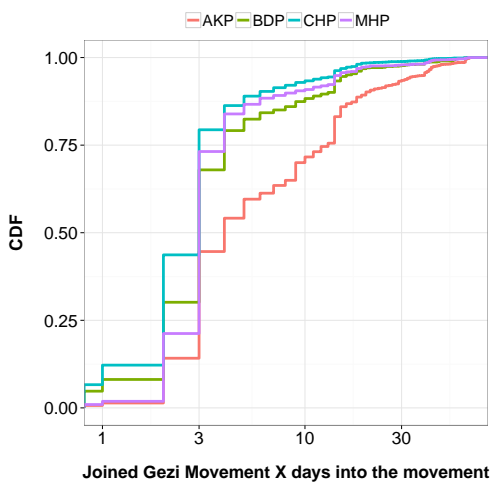

(c) First Involvement in the Gezi uprising

Figure 3: Comparative analysis of various party supporters, focusing on Gezi involvement

to settle the issue, we note simply that there is a clear analytical distinction between people who protest exclusively through social media and those who participate physically in protests. Physical participation, moreover, also has implications for the question of influence: although social media users are free to engage in conversation with people from different backgrounds, the physical proximity of an actual protest site is more likely to force such engagement (McAdam, 1989).

Bearing in mind the importance of physical participation, both with respect to selection and to change, we seek to distinguish between protesters who participated in the uprising only through social media and those who participated in physical protests. To this end, we leverage the widespread activist use of Foursquare checkins during Gezi uprising as a "proof" of physical participation and as a form of social pressure to nudge others to join them. ${ }^{25}$ Specifically, we focus on tweets that were tagged with one of the uprising hashtags and included a Foursquare check-in to identify physical protest participation. In this manner, we identified a subset of 471 users in our panel (3 percent) as "physical participants," for which Table 3 shows the corresponding breakdown by political party. The low percentage of physical participation reinforces the notion that online activism and physical participation are quite different (Lewis, Gray, and Meierhenrich, 2014).

\section{A Note on Data Quality vs. Quantity}

Proponents of social media data often focus on its scale, which frequently dwarfs that of traditional social science data. Critics of social media data, meanwhile, tend to focus on its quality, which is often subject to problems such as lack of representativeness or completeness (Tufekci, 2014), high variability over time and/or across individuals (Salganik and Levy, 2012), and absence of relevant outcome variables (Diaz et al., 2015). In constructing a panel out of what is effectively a convenience sample of Twitter users we have attempted to strike a balance between data quantity and quality, on the one hand leveraging the low cost and "always on" nature of Twitter data while on the other hand alleviating potential sources of 
Table 4: Categories of users and tweets in study. For each category of users, we list the number of relevant tweets; i.e. for \#Gezi participants we list the number of Gezi related tweets, and for the last four rows we list the number of MP retweets.

\begin{tabular}{lrr}
\hline Category & $\begin{array}{c}\text { Number of } \\
\text { Users }\end{array}$ & $\begin{array}{c}\text { Number of } \\
\text { Relevant Tweets }\end{array}$ \\
\hline \#Gezi Participants & $1,289,320$ & $12,070,622$ \\
Retweeted $\geq 1$ MP tweets prior to Gezi & 333,349 & $7,434,124$ \\
Retweeted $\geq 10$ MP tweets prior to Gezi & 31,518 & $2,516,530$ \\
Panel Members & 30,323 & $2,459,635$ \\
Physical Protest Participants & 471 & 35,606 \\
\hline
\end{tabular}

error. As Table 4 shows, the resulting panel is still large by traditional standards, comprising over 30,000 members, but it is several hundred times smaller than the population of Turkish Twitter users with which we began, and over 40 times smaller than the total number of Twitter users who participated in \#Gezi in any manner. In discarding the vast majority of Twitter users, however, our method yields two gains that are critical to our analysis: (1) we can reliably classify our panel members' political affiliations; and (2) we can track within-individual changes in political affiliation over the entire course of the movement. Moreover, although we cannot guarantee that our sample is representative of the Turkish population in general, or even the subpopulation who participated in the Gezi uprising, we can at least verify that their geographical distribution and party affiliations closely resemble those of the general population, lending some credibility to our results. Finally, our sub-panel of users with Foursquare check-ins yields an even smaller number (just 471 members), but it too carries an important advantage, allowing us to compare virtual with physical participation. Thus although in an ideal world we would have very large samples of opinions that are also representative and relevant to the question of interest, we propose that our ex post panel method strikes a reasonable and useful tradeoff between various real-world constraints.

\section{Results}

With our panel constructed, our analysis now proceeds in two stages. First, we perform a number of tests on our data to check both that our method for identifying party affiliation and also our method for identifying participation in the \#Gezi movement generate sensible results. In the process, we find evidence in support of our selection hypothesis-namely that supporters of all four parties who participated in \#Gezi were less supportive of both their own parties and the governing AKP party than non-participants. Second, we present our main analysis of influence versus selection effects among the three main opposition parties, finding evidence that both mechanisms are important but that selection may be more important. 


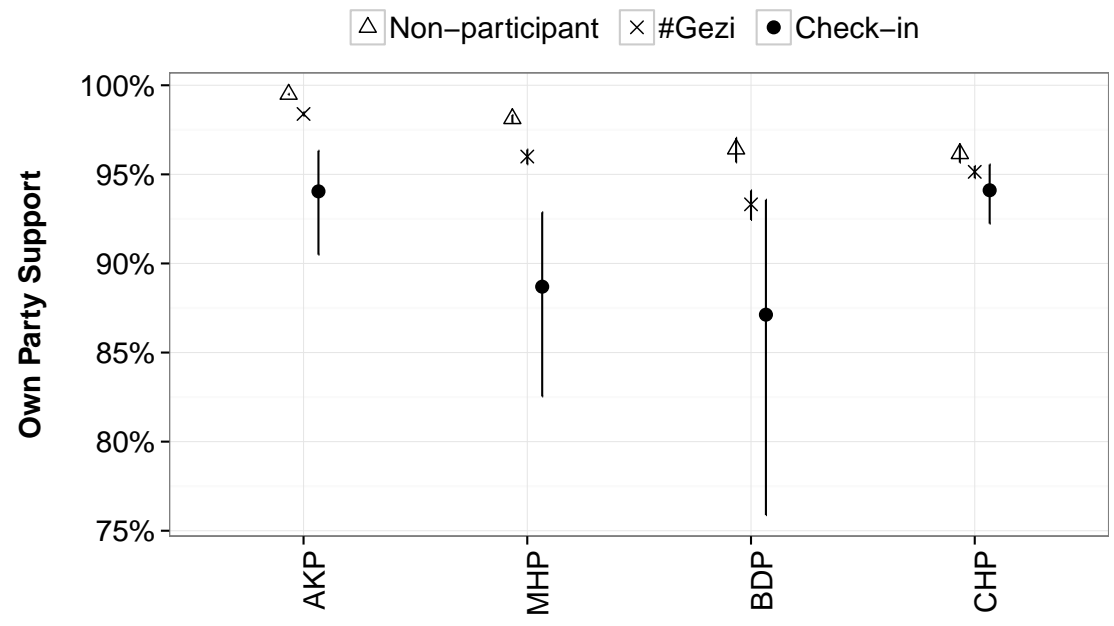

Figure 4: Own Party Support During Gezi. The x-axis is ordered by increasing Gezi participation (given in second column of Table 3) and markers defining Gezi participation are ordered in a similar fashion, in increasing order: "non-participant", "\#Gezi", and "Check-in." Error bars mark confidence intervals

\section{Own-Party and AKP Loyalty}

To test the robustness of our party affiliation identification, we check that users identified as supporters of a given party pre-Gezi continued to support their party during the movement. Specifically, we fit a multivariate linear mixed model as implemented by Bates et al. (2014) that estimates the ex ante probability of each party retweet, $R T_{i}$ during Gezi, being in support of the party the user is affiliated with according to our identification method (see section Own Party Support in the appendix for details.) The results are given in Figure 4, which shows the estimated probability (expressed as a percentage) of a user supporting his or her own party, where "support" is defined here as a retweet of a PM of the relevant party, broken down by party affiliation and three levels of \#Gezi participation (non-participant; \#Gezi, i.e. Gezi participants without protest check-ins; or check-in, i.e. Gezi participants with protest check-ins). Figure 4 shows that all subgroups exhibit over 80 percent support for their own party, suggesting that our party identification method is indeed robust. A more detailed look also reveals that AKP (government) supporters are the most dedicated to their own party, followed by Turkish nationalists (far right MHP and center-left CHP), and finally BDP supporters (far left Kurdish nationalists), who were in general the least dedicated to their own party. Also interesting in light of our question about selection effects, Figure 4 shows that users who participated in \#Gezi were less dedicated to their own parties compared to non-participants, and hence presumably more likely to be open to the other parties. We further note that Figure 4 shows that physical participants (i.e., those with Foursquare check-ins) were less dedicated than virtual participants, where interestingly these differences are consistent across all four major parties, including the AKP. 


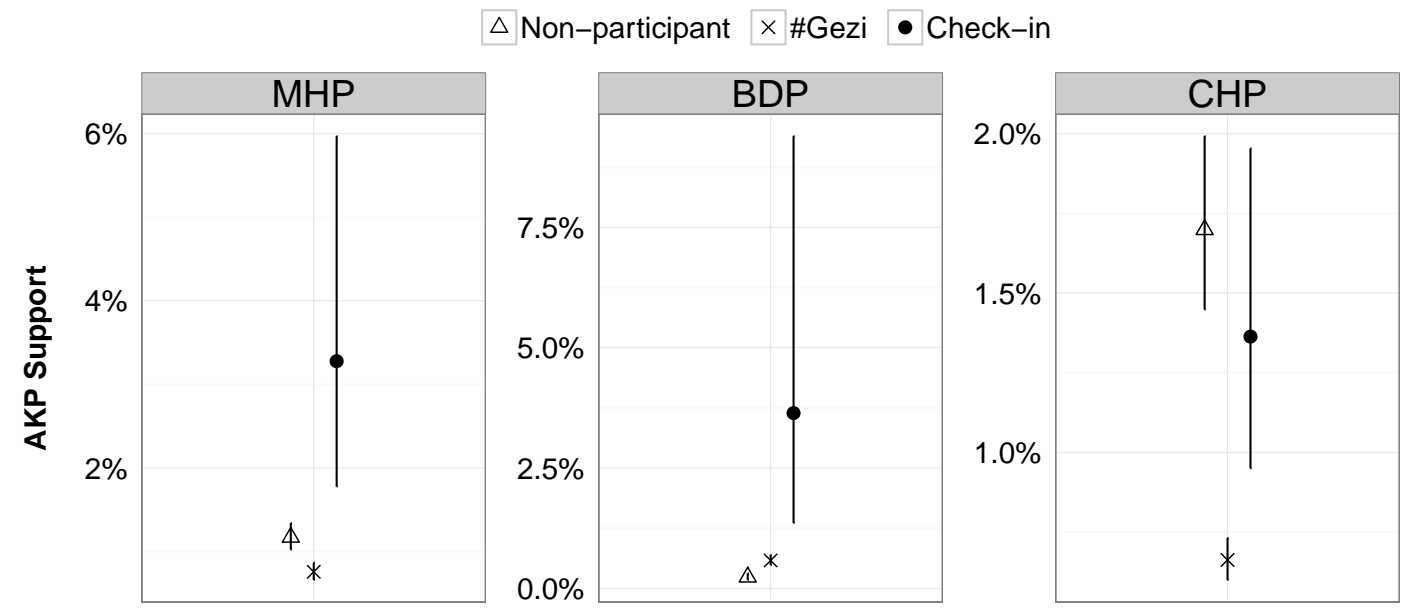

Figure 5: AKP Support Before Gezi across different groups: Error bars mark confidence intervals based on fixed-effect variations.

In addition to checking for own-party loyalty, we also expect that support for the AKP government (quantified as the likelihood of an AKP politician retweet) will be low among the three opposition parties; and that users identified as Gezi participants will be less supportive of AKP than non-participants. Through a mixed-effects model similar to the one used to measure own-party support (see AKP Support in the appendix for details), we estimate the ex ante probability for each party retweet prior to Gezi being in support of AKP. The results are shown in Figure 5, which comprises three panels, one each for supporters of the main opposition parties. ${ }^{26}$ Each panel in turn includes three predictions for the three possible levels of \#Gezi participation (non-participant, \#Gezi, check-in). As hypothesized, users associated with the opposition CHP, BDP, and MHP parties show negligible support for the AKP, albeit differently for each party. Moreover, the effect of \#Gezi participation is more subtle than for AKP: although we observe lower AKP support among $\mathrm{CHP}$ and MHP supporters who would choose to participate in \#Gezi compared to their non-participant counterparts, we do not observe this pattern for the BDP (see Eclectic BDP subgroup in the appendix for additional discussion). We also see that users who participated in physical protests have higher support for the AKP than other \#Gezi participants, suggesting that opposition to the AKP government better describes purely online activists than those who participated in the physical protests. These results add some nuance to the commonly expressed view of the \#Gezi movement as unified only by opposition to the AKP government, showing that not everyone was equally opposed, nor was opposition related to participation in a straightforward manner. Nevertheless, Figure 5 clearly indicates that overall support for the AKP was extremely low among the opposition parties, and that the average effect of \#Gezi participation on AKP support irrespective of party affiliation is negative, both of which are consistent with other evidence. 


\section{Influence versus Selection Among Opposition Parties}

Figures 4 and 5 already provide evidence that participants in \#Gezi were different from non-participants, being less supportive of their own parties and also less supportive of the AKP. With these preliminary results in mind, we now turn to our central question: to what extent was the observed solidarity among the supporters of the main opposition parties a result of biased selection into the movement (i.e., preexisting affinity), versus influence of the movement itself (i.e., opinion change)? In addition, we examine the impact of physical participation, as indicated by Foursquare check-ins, versus virtual participation indicated by hashtag usage.

Examining first the selection hypothesis, we estimate the affinity of the opposition party (CHP, MHP, and BDP) supporters towards each other's parties prior to the uprising (see Selection: Estimating pre-Gezi affinity in the appendix for model details). The results are given in Figure 6, which shows the affinity of each opposition party towards the other opposition parties grouped by level of participation-e.g. an affinity of $y=1 \%$ means that the probability that a retweet issued by a user with the corresponding characteristics (party affiliation and Gezi participation) would be in support of the other two opposition parties prior to Gezi is estimated as 0.010 through our model ${ }^{27}$. Figure 6 supports two high level conclusions. First, irrespective of party affiliation, users who participated in Gezi were already more likely to show more affinity towards the other opposition parties before the movement. For instance, BDP (far left party) supporters who participated in the movement exhibited roughly double the support for the CHP (center left) or the MHP (far right) relative to those who would choose not to participate. A similar effect size is observed for MHP supporters and a slightly lower effect-about a 50\% increase-is observed for CHP supporters. Second, we observe that the relationship between online and physical participation is less consistent: whereas BDP and CHP supporters who participated in \#Gezi are indistinguishable from those who also registered their physical presence, MHP supporters who participated in physical protests were roughly twice as likely to show preexisting affinity towards the other opposition parties relative to those who simply participated online.

Next, Figure 7 examines the influence hypothesis, showing changes in affinity towards other opposition parties by comparing retweet behavior prior to, during, and after the movement (see Emergence: Estimating change during and after Gezi in the appendix for model details). Focusing first on MHP supporters (top panel), we observe that non-participants do not experience a significant change in affinity from before to during the Gezi uprising, while \#Gezi participants show a boost in affinity from two percent to four percent, and physical participants (indicated by Foursquare check-ins) display a boost from six percent to 13 percent (both differences are statistically significant). Turning to BDP supporters (middle panel), we see a similar pattern: the difference between non-participant behavior before and during the movement is not statistically different (i.e., it is within error bounds), while participants experience a significant boost in affinity. Specifically, virtual participants show doubled affinity (prior $=$ six percent, during $=12$ percent), while those who participated in physical protests show a jump from seven percent affinity prior to the Gezi uprising to 24 percent during it. Finally for CHP supporters (bottom panel) we once again find no significant difference for non-participant 


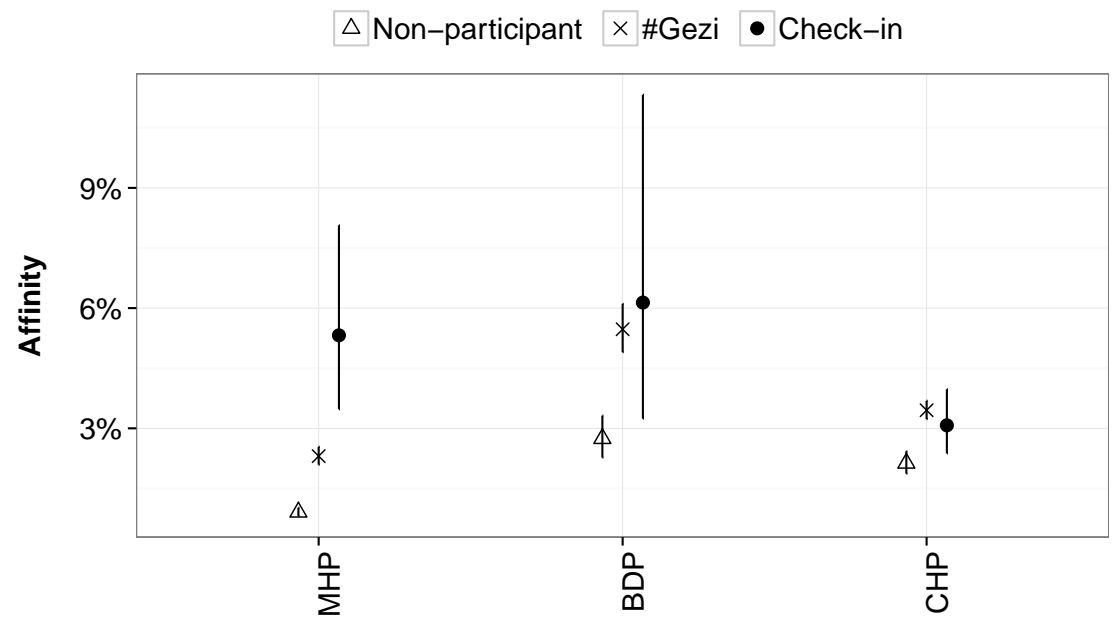

Figure 6: Affinity Before Gezi: Error bars mark confidence intervals

behavior prior to and during the movement. Unlike for BDP and MHP supporters, however, the difference for participants is also rather small (though significant), and the difference for participants with physical participation is not significant.

Figure 7 also sheds light on the persistence of these changes. Genuine shifts in opinion may nevertheless be temporary if they arise from transient alliances of convenience or if they represent usage of Twitter simply to disseminate informationfor example, a BDP supporter might retweet a CHP MP tweet only because it includes facts about the Gezi movement. While such indications of support are not meaningless, they are likely to disappear once the protests come to an end. Alternatively, the observed changes could represent lasting changes of opinion or perspective, in which case we would expect them to persist. Overall, the results presented in Figure 7 show that affinity indeed declines slightly after the movement ends, yet remains higher than the affinity measured before the movement. Thus although some of the solidarity observed during the movement was temporary, it also appears that some amount of change persisted, at least for certain subgroups. In particular, we observe that the affinity measured for BDP and MHP supporters who participated in \#Gezi and those who also participated in the physical protests are both significantly higher than the affinity estimated for those subgroups prior to the movement, and rather similar to the affinity seen during the movement. As with the analysis above, however, CHP protesters with check-ins exhibit no statistically significant difference between the behavior prior to and after the movement. In addition, the increase in affinity observed for CHP supporters with no check-ins disappears after the movement is over.

In summary, we find evidence both for selection (Figure 6) and influence (Figure 7), but find that only selection is a significant factor for the observed solidarity of the Gezi movement across all opposition parties. In contrast, influence, as measured by changes taking place within groups over the course of the movement, 


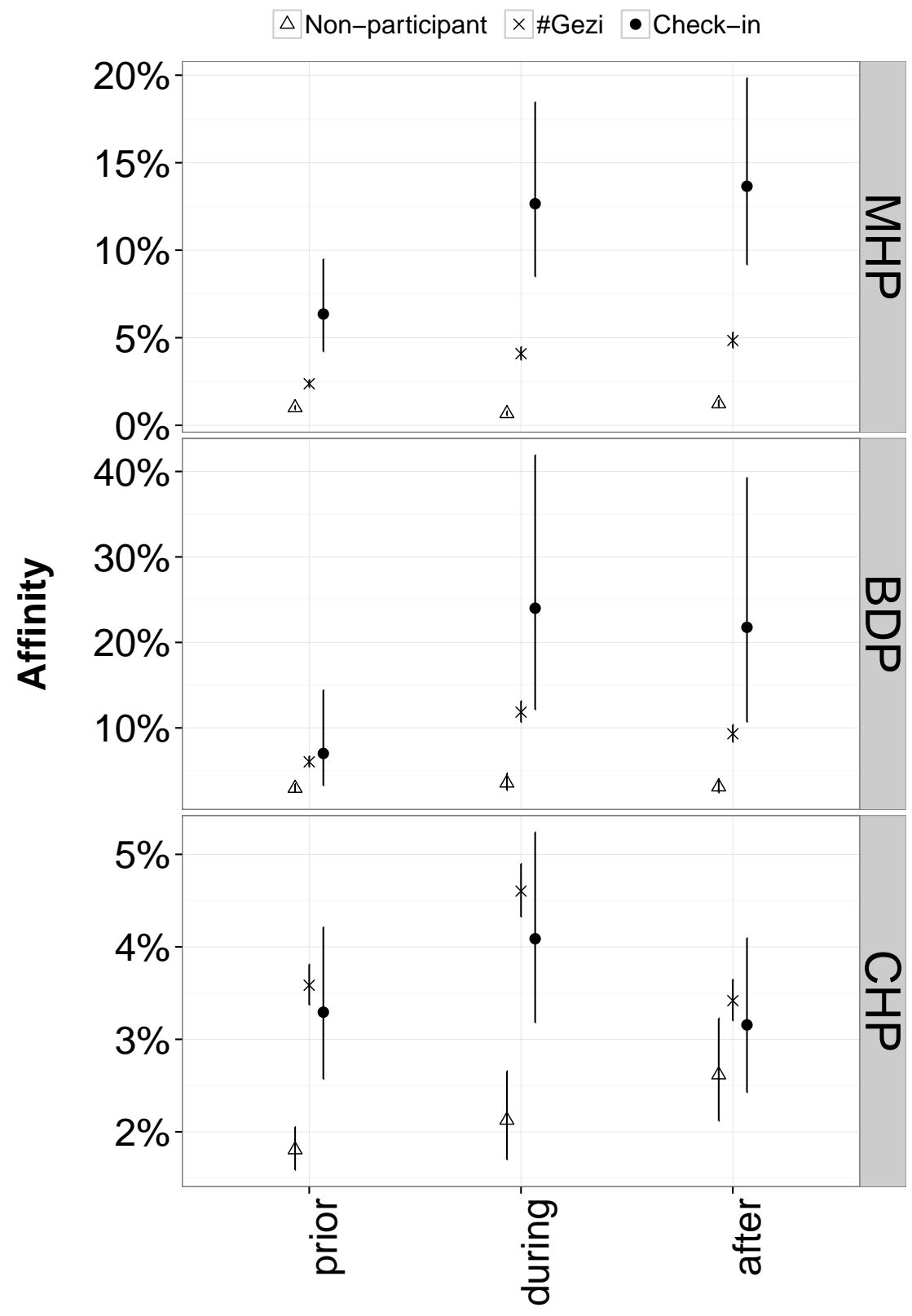

Figure 7: Changes in affinity between opposition parties over time. Model estimates are shown before, during, and after the Gezi movement, where each vertical panel shows the estimated affinity (probability of retweet of the other opposition parties) for the supporters of the labeled party. In addition, there are three different predictions presented for each such subgroup; estimated affinity for non-participant, participant, and physical participants, where confidence intervals indicate the fixed-effects errors. 
is only significant for BDP and MHP supporters. Specifically, we find the largest effect for BDP supporters who participated in the physical protests, followed by MHP supporters who participated in physical protests, suggesting that at least in some cases online versus offline activism do indeed have different implications. The results therefore support the conventional wisdom that at least some participants did in fact become sympathetic to each other's views, but also highlight a point that is missed in by the usual narrative-namely that the participants were qualitatively different from their fellow party supporters who chose not to participate in the movement. Specifically, future Gezi participants were already more likely to show affinity towards the other parties before the movement, and so were not so unlikely of a group to come together after all.

\section{Robustness Checks}

Here we discuss the limitations of our approach and present robustness checks to address possible concerns. The first concern we address relates to our approach of identifying political affiliation - that in order to construct a panel whose political attitudes can be identified accurately, we limited our analysis to users who had at least ten MP retweets prior to the Gezi movement. While a threshold is helpful for our analysis, the threshold of ten is somewhat arbitrary. Therefore, we performed sensitivity analysis to test whether the findings were robust with respect to the choice of this threshold $\theta$. First, we compared the distribution of users across parties (column 2 in Table 3) for different threshold values $(\theta \in\{5,6,7,8,9,10\})$ and found the minimum pairwise correlation to be 0.999 . Next, we repeated the entire analysis presented in Own-Party and AKP Loyalty and Influence versus Selection Among Opposition Parties with threshold $\theta=5$. The correlation between the results summarized in Figures $4,5,6$, and $7(\theta=10)$ and the corresponding results when $\theta=5$ were $0.981,0.999,0.980,0.994$, and 0.996 , indicating that the qualitative findings are robust to the choice of threshold.

Another point of concern is the use of Foursquare check-ins to measure physical protest participation, as there certainly may be panel members who participated in physical protests but did not share this fact through a Foursquare check-in. Such omissions might cause problems for our analysis for two reasons: (1) people who use Foursquare in general might be qualitatively different from those who do not; and (2) people who use Foursquare in general may choose not to use it when protesting out of fear of discovery. Here we address the first point, identifying all Foursquare users in our panel (i.e., not just those whose Foursquare usage is associated with \#Gezi) as follows: a panel member is labeled as a Foursquare user if he has at least one tweet with a Foursquare check-in prior to the end of the movement, irrespective of the location of the check-in or the topic of the tweet. This selection criterion yields 10,567 "general Foursquare users" out of 30,323 panel members. In order to investigate whether affinity and change estimated is affected by this characteristic, we extend our models to control for this measure by simply adding a dummy variable that is coded as 1 if the user is a Foursquare user and 0 otherwise. The results indicate that affinity and change in affinity are not related to this measure (i.e. the estimation of the extended models consistently mark this 
predictor as small and statistically insignificant). With respect to the second potential problem - that fear of repression dissuades protesters from broadcasting their physical location-we are unfortunately not able to evaluate directly how serious a problem it is. We note, however, that the trials against Twitter users who participated in the movement through Twitter ${ }^{28}$ suggest that Twitter participation alone was a form of high risk protest; thus although some additional censoring of physical participation still seems likely, we hope that bias introduced will be small relative to other effects we have observed.

\section{Discussion}

Studies of social movements have traditionally relied on ethnographic methods such as participant observation and interviews to learn about the motives and attitudes of participants. These methods are powerful, especially for extracting thick descriptions of the lived experience of a movement, but they are also limited in two key respects. First, because they sample only active participants they are unable to draw objective comparisons with non-participants and hence are limited in their ability to identify the predictors of participation. Second, by construction participants can only be observed or interviewed after the movement has begun; hence objective comparisons with preexisting beliefs and attitudes are difficult.

In this article, we have introduced an alternative method for studying the dynamics of social movements that exploits a relatively recent source of data, namely Twitter, in the context of the 2013 Gezi uprisings in Turkey. Specifically, by constructing a panel of politically engaged users each of whom we then classify in terms of political party, participation in the \#Gezi movement, and physical participation in the movement, we can detect preexisting differences in affinity for each such subgroup as well as changes in affinity over the course of the uprising. In this manner we can shed light on processes that would not be apparent from even carefully conducted surveys or interviews. For example, our finding that participants in the \#Gezi movement showed greater affinity for other opposition parties (relative to non-participants) even prior to the onset of the movement-and that the effect was stronger for participants who identified themselves as physically present at Gezi park-suggests that at least some of the spirit of Gezi that was observed by onlookers reflected the preexisting attitudes of the participants. Moreover, while BDP and MHP-affiliated participants did show an increase in support for the other parties-a striking increase for physically present participants-CHP-affiliated participants did not. In addition, we were able to determine heterogeneity in activist participation by identifying a subset of \#Gezi activists who also participated in physical protests through the use of Foursquare check-ins. Using this data, we detected differences in preexisting attitudes and changes in attitude for the corresponding activist subgroups, in turn suggesting fundamental distinctions between online and offline activists.

Although we have used our panel method to study just a single case of a social movement-the 2013 Gezi uprising in Turkey—we note that the method itself is relevant both to other social movements and to other instances of unexpected opinion change. The reason is that the "always on" nature of Twitter allows researchers 
to construct ex post panels of the sort we have introduced here months or even years after the events of interest have taken place, making it especially attractive for studying events such as political uprisings that are hard, if not impossible, for researchers to anticipate and so do not lend themselves to traditional, ex ante panel designs. Moreover, hashtag usage is extremely common on Twitter for signaling interest in a topic and so can be used to identify participation in conversations of many different types. Likewise, identifying affinity by observing which users a given user chooses to retweet could easily be applied in other political contexts and even in non-political contexts. We hope that future work will adopt the use of large-scale panels drawn from social media data to analyze other social movements, eventually allowing for cross-national and cross-domain (e.g., political versus social, violent versus non-violent) comparative studies. Moreover, future studies could delve deeper into the content of conversations by leveraging techniques from natural language processing as well as the presence of structured data like URLs that frequently appear in social media posts.

In spite of its generality, we emphasize that our approach is not intended to replace traditional methods for studying social movements, but rather to complement them. As we have repeatedly noted, Twitter data is potentially incomplete or biased in numerous respects (Diaz et al., 2015), and hence must be carefully preprocessed before any conclusions are drawn. Because this process necessarily relies on the existence of sources of "ground truth" data such as surveys, interviews, and electoral records, our approach is intrinsically complementary to traditional methods. We also note that our method of ex post panel construction exhibits certain intrinsic limitations. For example, it would have been desirable to identify the political affiliations of panel members using followership data (which politicians a user follows) as well as retweet behavior (which politicians a user retweets); however, unlike tweets, followership data is not available historically, but can only be obtained through Twitter's API at the time of interest. Going forward, researchers could regularly crawl Twitter's follower graph in anticipation of future panels; however such an exercise is expensive in both time and memory and still does not guarantee that all features of interest ex post will be collected ex ante.

Finally, in addition to motivating future methodological work, we hope that our substantive findings will provoke additional theoretical work in the area of social movements. For example, while most collective action models conceptualize a movement as actions taken by a rather homogenous group of activists who come together for a common goal, we observed that Gezi brought together a rather heterogenous group of participants who differed in fundamental characteristics such as their political affiliations. What does such heterogeneity imply for the success of a movement? Furthermore, should one consider opinion change caused by the movement in its participants a success measure? While the measures proposed by Gamson (1975) would suggest that Gezi Park protestors by-and-large failed at their mission, the solidarity formed—as observed in data-can be thought of as an unintended positive consequence (Tilly, 1999), one that can have larger implications than the goal of the movement itself. We hope further research that spans various movements will provide a generalizable answer to such questions. In addition, 
we hope the understanding built through the study of these movements will be incorporated into theoretical models of social movements.

\section{Notes}

1 For example, the Atlantic described the participants as "the young and the old, the secular and the religious, the soccer hooligans and the blind, anarchists, communists, nationalists, Kurds, gays, feminists, and students." Der Spiegel said that protests were "drawing more than students and intellectuals. Families with children, women in headscarves, men in suits, hipsters in sneakers, pharmacists, teahouse proprietors, all are taking to the streets to register their displeasure... Kemalists and communists have demonstrated side-by-side with liberals and secularists..." The Guardian observed that "Flags of the environmentalist movement, rainbow banners, flags of Atatürk, of Che Guevara, of different trade unions, all adorn the Gezi park." Hürriyet reported that even the football supporter clubs of the three major teams, normally greatly antagonistic towards each other, had agreed to join the protests together. And the Economist noted that there were as many women as men, and said that "Scenes of tattooed youths helping women in headscarves stricken by tear gas have bust tired stereotypes about secularism versus Islam."

2 For example, White (2013) writes, "Like a snowball rolling downhill, state violence and exasperation with the prime minister's tone-deaf intransigence has managed to unite groups that in the past believed they had very little in common or were at odds with one another." Kuymulu (2013) writes, "The uprisings that caught the AKP government off-guard brought together an unlikely body of people from all walks of life for the first time in recent memory." Sözalan (2013) writes, "People seem to have learned the hard way; the solidarity between groups that had been so far set against one another has led to the understanding that we need to not only hear, but listen to each other and resist isolation." And Sayers (2014) writes "During the occupation... these disparate, protesting groups learned to respect each other's space and opinions, joined marches for each other's causes, made fun of each other's ideological cliches, and stopped allowing the traditional faultlines of Turkish politics to determine who they had to be allies and enemies with."

3 Clearly researchers could attempt to survey non-participants, and also ask participants about their preexisting attitudes, but: (1) it is unclear how to sample non-participants in a way that compares naturally to the participant sample; and (2) participants' recall of their previous attitudes would almost certainly be biased by their experiences in ways that would be hard to adjust for.

4 Schussman and Soule (2005) used a similar design-a two-stage panel constructed from a nationally representative survey - to answer a related but somewhat different question, namely the factors predicting protest participation.

5 McAdam did not compare the attitudes of those who applied with those who did not, and thus could not say to what extent both participants and no-shows differed from the broader population.

6 In some sense all social measurement technologies have this dual role-for example, the results of public opinion surveys can influence the subsequent evolution of the very opinions they seek to measure. Social media, however, is qualitatively different from other measurement technologies in that its measurement function is largely a byproduct of its use, rather than its intended purpose. 
7 Etling (2013) also cites the Stop Online Piracy Act (SOPA), Protect-IP Act (PIPA), and Anti-Counterfieting Trade Agreement (ACTA) as victories of online activism.

8 Controlling for other factors, Tufekci and Wilson (2012) find that protesters who used social media were more likely to participate in the first day of protests compared to those who got their news from traditional news media.

9 Khamis and Vaughn (2011) also underline the importance of these tools in providing political networking opportunities and supporting the capability of the protestors to plan and execute protests.

10 González-Bailón, Borge-Holthoefer, and Moreno (2013) also suggest that new forms of social movements coordinated by online networks do not conform to traditional models of collective action. They argue that the costs of online participation are lower relative to offline, hence mechanisms to limit selfish rationality and to encourage participation no longer apply.

11 Etling et al. (2009) could also be included in the first category of studies that highlight social media as a causal factor driving movements, as they ask the following question "Can social media empower social movements that can move Arab societies toward democratic values and governance?"

12 A similar method has been proposed by Diaz et al. (2015) in the context of public opinion polling.

13 We use hashtags that start with \#direngezi, \#occupygezi, or \#geziparki to match a broader set including, for example, \#direngeziseninleyiz (resist Gezi, we are with you). We also note that our study is focused on positive participation in the movement and therefore we chose hashtags that identify the supporters of the Gezi movement as opposed to its opponents (although as we show later, some opponents used the same hashtags, thereby requiring separate treatment).

14 See, for example, http://amnesty . org/en/for-media/press-releases/turkey-gezipark-protest-twitter-trial-2014-04-17

15 It may also be interesting to study the politicization of previously apolitical actors, but we leave such a study for future work.

16 We note that compositional changes and differences in activity levels of individuals introduce somewhat different sources of bias and hence require separate solutions. Aggregating over time, for example, would not alleviate the bias introduced by some individuals persistently being more active than others, while conversely mixed-effects models estimated on a daily basis, say, would not fully correct for different types of individuals being active on different days. The latter problem could also be addressed by post-stratification (i.e., re-weighting to simulate a consistent distribution over types), but daily snapshots are unnecessarily granular for our purposes; hence we opt for the simpler approach of aggregation.

17 Strictly speaking, only three of the parties satisfied the 10 percent threshold. BDP members exploited a loophole in the threshold rule that exempts candidates who run as independents. Once elected, however, nominal independents can announce themselves to be members of a political party-they just cannot run for election as such. BDP politicians generally have high support in Eastern Turkey, while the total vote share of the party across Turkey is commonly less than 10 percent. At the time of the writing of this article, most BDP members have migrated to a new party (HDP) with similar ideological positions.

18 We only consider Parliament members who were active before the Gezi movement in order to avoid confounding change in Parliament member presence with the change in 
their support in the population. Tweets of the discovered Twitter accounts are inspected to filter out Twitter accounts created by those other than the MP herself.

19 The resemblance of Twitter representation and corresponding election results was also observed for the U.S. politics by Tumasjan et al. (2010).

20 While there certainly are other forms of political engagement, in this study we focus on engagement with political parties for two main reasons: (1) given the stark differences between political parties and the indifferent-at times hostile-attitude of their supporters towards each other, observing solidarity among these political groups is itself interesting; and (2) availability of electoral data provides ground truth about these political groups, enabling us to put our work in a larger context.

21 In principle, one could also identify party support by examining which MPs a given user follows. However, Twitter's API only provides the means to extract the followers of a particular person at the time that the system is queried; hence we cannot identify followership retrospectively.

22 We performed sensitivity analysis to test whether our findings were robust with respect to the choice of this threshold. Details are provided in Robustness Checks.

23 Although it may seem surprising that more than half of our panel, who by construction are disproportionately engaged in political discourse, do not ever participate in \#Gezi, we note that the participation rate among panel members is nevertheless roughly four times that among the active Turkish Twitter population (11 percent).

24 Given the critique that the protesters drop the hashtag over time while still talking about the movement, this measure of duration is likely an underestimate, but is still useful for measuring relative involvement across groups.

25 Foursquare is a social location-sharing mobile application that at the time allowed users to post their exact location to Twitter. Once a Foursquare user checks in to a location, that is, she is also able to share this information with her friends on other social platforms, such as Facebook or Twitter, with a simple click of a button. This study was done before Foursquare became a pure UGC (user-generated content) platform to share reviews.

26 We do not compute AKP support among AKP supporters prior to Gezi, as this figure is captured in Figure 4

27 More precisely, we estimate the ex-ante probability of: (1) a CHP supporter retweeting an MHP or BDP MP tweet; (2) an MHP supporter retweeting an CHP or BDP MP tweet; and (3) a BDP supporter retweeting a CHP or MHP MP tweet prior to Gezi (see the appendix for details of the model).

28 http: //www. amnesty.org/en/for-media/press-releases/turkey-gezi-park-protesttwitter-trial-2014-04-17.

\section{References}

Abramowitz, Stephen I., and Alberta J. Nassi. 1981. "Keeping the faith: Psychosocial correlates of activism persistence into middle adulthood." Journal of Youth and Adolescence 10(6):507-523. http://dx . doi .org/10.1007/BF02087943.

Atay, Tayfun. 2013. "The Clash of Nations in Turkey: Reflections on the Gezi Park Incident." Insight Turkey 15(3):39-44.

Bates, Douglas, Martin Maechler, Benjamin M. Bolker, and Steven Walker. 2014. "lme4: Linear mixed-effects models using Eigen and S4." arXiv:1406.5823 [stat.CO]. 
Bezmez, Dikmen. 2013. "Urban social movements in Turkey." Open Citizenship 4(2).

Collective, ROAR. 2014. "Beyond Gezi: What Future for the Movement?" http://roarmag. org/2014/01/beyond-gezi-future-movement.

Demerath, Nicholas Jay, Gerald Marwell, and Michael T. Aiken. 1971. Dynamics of idealism: White activists in a Black movement. San Francisco: Jossey-Bass.

Diaz, Fernando, Michael Gamon, Jake Hofman, Emre Kiciman, and David Rothschild. 2015. "Online and social media data as an imperfect continuous panel survey." Unpublished manuscript.

Economist, The. 2009. "Turkey and the Kurds: Return of the natives." http://www . economist. com/node/14710708.

Ete, Hatem. 2013. “The Political Reverberations of the Gezi Protests." Insight Turkey 15(3).

Etling, Bruce. 2013. “Citizens as Actors." Internet Monitor 2013: Reflections on the Digital World 27.

Etling, Bruce, John Kelly, Robert Faris, and John Palfrey. 2009. Mapping the Arabic blogosphere: politics, culture, and dissent. Internet \& Democracy Project, Berkman Center for Internet \& Society.

Fendrich, James M. 1974. "Activists Ten Years Later: A Test of Generational Unit Continuity." Journal of Social Issues 30(3):95-118. http://dx . doi .org/10.1111/j .1540-4560. 1974.tb00729.x.

Fendrich, James M. 1977. "Keeping the faith or pursuing the good life: A study of the consequences of participation in the civil rights movement." American Sociological Review 42(1):144-157. http://dx.doi .org/10.2307/2117736.

Fendrich, James M., and Alison T. Tarleau. 1973. "Marching to a different drummer: Occupational and political correlates of former student activists." Social Forces 52(2): 245-253. http://dx.doi.org/10.1093/sf/52.2.245.

Fendrich, James M., and Ellis M. Krauss. 1978. "Student activism and adult left-wing politics: a causal model of political socialization for black, white and Japanese students of the 1960s generation." Research in Social Movements, Conflicts, and Change 1: 231-55.

Gamson, William A. 1975. The Strategy of Social Protest. Homewood, IL: Dorsey Press.

Gelman, Andrew, and Jennifer Hill. 2006. Data Analysis Using Regression and Multilevel/Hierarchical Models. Cambridge: Cambridge University Press. http://dx.doi .org/ 10.1017/CB09780511790942.

Genar. 2013. “Gezi Parki Profili." http://genar.com.tr/files/geziparki_profile-son. pdf.

Gleason, Benjamin. 2013. “\#Occupy Wall Street: Exploring informal learning about a social movement on Twitter." American Behavioral Scientist 57(7):966-982. http://dx.doi .org/ $10.1177 / 0002764213479372$.

González-Bailón, Sandra, Javier Borge-Holthoefer, Alejandro Rivero, and Yamir Moreno. 2011. "The dynamics of protest recruitment through an online network." Scientific Reports 1. http://dx.doi.org/10.1038/srep00197. 
González-Bailón, Sandra, Javier Borge-Holthoefer, and Yamir Moreno. 2013. “Broadcasters and hidden influentials in online protest diffusion." American Behavioral Scientist 57(7):943965.

Hanna, Alexander. 2013. “Computer-Aided Content Analysis of Digitally Enabled Movements." Mobilization: An International Quarterly 18(4):367-388.

Hürriyet. 2013. "Timeline of Gezi Protests." http://www.hurriyetdailynews.com/ timeline- of -gezi-park-protests - aspx?pageID=238\&nID=48321\&NewsCatID=341.

Jennings, M. Kent, Gregory B. Markus, Richard G. Niemi, and Laura Stoker. 2005. "Youth-parent socialization panel study, 1965-1997: four waves combined." http:/ / doi.org/10.3886/ICPSR04037.v1

Kemp, Simon. 2015. “Digital, Social \& Mobile Worldwide in 2015." http: //wearesocial . net/blog/2015/01/digital-social-mobile-worldwide-2015.

Khamis, Sahar, and Katherine Vaughn. 2011. "Cyberactivism in the Egyptian revolution: How civic engagement and citizen journalism tilted the balance." Arab Media and Society 13(3).

Konda. 2014. "Gezi Raporu." http://www.konda.com.tr/tr/raporlar/KONDA_ GeziRaporu2014.pdf.

Kuymulu, Mehmet Bariş. 2013. "Reclaiming the right to the city: Reflections on the urban uprisings in Turkey." City 17(3):274-278. http://dx.doi.org/10.1080/13604813.2013. 815450.

Lewis, Kevin, Kurt Gray, and Jens Meierhenrich. 2014. "The structure of online activism." Sociological Science 1:1-9. http://dx.doi.org/10.15195/v1.a1.

Maidenberg, Michael, and Philip Meyer. 1970. "The Berkeley rebels: Five years later." Public Opinion Quarterly 24:477-78.

Marwell, Gerald, Michael T Aiken, and NJ Demerath. 1987. “The persistence of political attitudes among 1960s civil rights activists." Public Opinion Quarterly 51(3):359-375. http: //dx.doi.org/10.1086/269041.

McAdam, Doug. 1989. "The biographical consequences of activism." American Sociological Review 54(5):744-760.

MetroPOLL. 2013. “Gezi Parki Protestolari." http://www.metropoll.com.tr/report/ gezi-parki-protestolari-haziran-2013.

Morozov, Evgeny. 2009. “The brave new world of slacktivism.” Foreign Policy 19(5).

Nassi, Alberta J., and Stephen I. Abramowitz. 1979. "Transition or transformation? Personal and political development of former Berkeley Free Speech Movement activists." Journal of Youth and Adolescence 8(1):21-35. http://dx. doi .org/10.1007/BF02139137.

Pew. 2012. "Social Networking Popular Across Globe." http://www .pewglobal .org/2012/ 12/12/social-networking-popular-across-globe.

Salganik, Matthew J., and Karen E. C. Levy. 2012. “Wiki surveys: Open and quantifiable social data collection." arXiv:1202.0500. 
Sayers, David Selim. 2014. "Gezi Spirit: The Possibility of an Impossibility." http: //roarmag. org/2014/01/gezi-ottoman-turkish-nationalism.

Schussman, Alan, and Sarah A Soule. 2005. "Process and protest: Accounting for individual protest participation." Social Forces 84(2):1083-1108. http://dx.doi.org/10.1353/sof . 2006.0034.

Sherkat, Darren E., and T. Jean Blocker. 1997. "Explaining the political and personal consequences of protest." Social Forces 75 (3): 1049-1070. http://dx.doi.org/10.1093/sf/75. 3.1049 .

Shulman, Stuart W. 2009. “The Case Against Mass E-mails: Perverse Incentives and Low Quality Public Participation in U.S. Federal Rulemaking." Policy E Internet 1(1):23-53. http://dx.doi.org/10.2202/1944-2866.1010.

Sözalan, Özden. 2013. "A Few Remarks on the Lessons of Gezi Uprising." Badiou Studies 2(1):146-151.

Starbird, Kate, and Leysia Palen. 2012. (How) will the revolution be retweeted?: Information diffusion and the 2011 Egyptian uprising. Paper presented at the Association of Computing Machinery Conference on Computer Supported Cooperative Work. http: //dx . doi .org/ $10.1145 / 2145204.2145212$.

Taştan, Coşkun. 2013. "The Gezi Park protests in Turkey: a qualitative field research." Insight Turkey 15(3):27-38.

The Grand National Assembly Deputy List. 2013. www.tbmm.gov.tr/develop/owa/ milletvekillerimiz_sd.liste.

Tilly, Charles. 1999. "From interactions to outcomes in social movements." Pp. 253-270 in How Social Movements Matter. Vol. 10 Social Movements, Protest, and Contention, edited by Guigni, Marco, Doug McAdam, and Charles Tilly. Minneapolis, MN: University of Minnesota Press.

Tufekci, Zeynep. 2014. “Big Questions for Social Media Big Data: Representativeness, Validity and Other Methodological Pitfalls." Paper presented at the International AAAI Conference on Web and Social Media.

Tufekci, Zeynep, and Christopher Wilson. 2012. "Social media and the decision to participate in political protest: Observations from Tahrir Square." Journal of Communication 62(2):363379. http://dx.doi.org/10.1111/j.1460-2466.2012.01629.x.

Tumasjan, Andranik, Timm Oliver Sprenger, Philipp G. Sandner, and Isabell M. Welpe. 2010. "Predicting Elections with Twitter: What 140 Characters Reveal about Political Sentiment." Paper presented at the International AAAI Conference on Web and Social Media.

Weber, Ingmar, Venkata R. Kiran Garimella, and Alaa Batayneh. 2013. Secular vs. islamist polarization in egypt on twitter. Paper presented at the IEEE/ACM International Conference on Advances in Social Networks Analysis and Mining. http://dx.doi.org/10. $1145 / 2492517.2492557$.

Whalen, Jack, and Richard Flacks. 1980. "The "Isla Vista" bank burners" ten years later: Notes on the fate of student activists." Sociological Focus pp. 215-236.

White, Jenny. 2013. "The Gezi Snowball: What a Difference a Week Makes." http: //kamilpasha. com/?p=7199. 
Acknowledgements: The authors are grateful to Sandra González-Bailón, David Rothschild, and Matthew Salganik for several helpful conversations as well as their extensive comments on an earlier version of this article.

Ceren Budak: Microsoft Research. E-mail: cbudak@microsoft.com

Duncan J. Watts: Microsoft Research. E-mail: duncan@microsoft.com 